\title{
Investigating silicon wafer based substrates for dried-droplet analysis by Laser-Induced Breakdown Spectroscopy
}

\author{
Nadir Aras, Şerife Yalçın* \\ Izmir Institute of Technology, Faculty of Science, Chemistry Department, 35430 Urla, Izmir, Turkey
}

\section{A R T I C L E I N F O}

\section{Keywords:}

Laser-induced breakdown spectroscopy

Dried-droplet analysis

Silicon wafer based substrate

Aqueous metal solutions

\begin{abstract}
A B S T R A C T
This work communicates a critical assessment on the analytical capability of the three silicon wafer-based substrates; crystalline silicon (c-Si), oxide-coated silicon $\left(\mathrm{SiO}_{2}-\mathrm{Si}\right)$, and nitride-coated silicon $\left(\mathrm{Si}_{3} \mathrm{~N}_{4}-\mathrm{Si}\right)$, for drieddroplet analysis by laser-induced breakdown spectroscopy. The methodology consists of loading, drying and analyzing steps. First, nanoliter volume of droplets are manually loaded onto the substrate and dried at room temperature. Then, the dry residue is subjected to high peak power $\left(1.15 \mathrm{GW} / \mathrm{cm}^{2}\right)$ laser pulses focused outside the minimum focal point condition and luminescent plasma is spectroscopically analyzed. Results revealed that nitride-coated substrate exhibits strong enhancements in signal intensity for most emission lines of the analyte species investigated: $\mathrm{Cd}, \mathrm{Cr}, \mathrm{Cu}, \mathrm{Mn}$, and $\mathrm{Pb}$. Surface reflectivity and surface morphology were comparatively investigated to explore enhanced analytical performance of nitride-coated substrates. Experimental conditions were optimized and growth curves for all the elements are found linear with minimum regression constant of 0.96. LOD's of $62 \mathrm{pg} \mathrm{Cd}, 1.5 \mathrm{pg} \mathrm{Cr}, 0.5 \mathrm{pg} \mathrm{Cu}, 2 \mathrm{pg} \mathrm{Mn}$ and $11 \mathrm{pg} \mathrm{Pb}$, in absolute amounts, were obtained. The accuracy and precision of the methodology were tested on certified reference water sample (CRM-TMDW), and ICP-multi-element standard sample (ICP-MES). The surface enhancement effect observed on $\mathrm{Si}_{3} \mathrm{~N}_{4}$ coated substrates has improved the analytical capability of laser-induced breakdown spectroscopy for liquid analysis.
\end{abstract}

\section{Introduction}

Laser-Induced Breakdown Spectroscopy, LIBS [1,2] is one of the most promising spectroscopic technique that enables simple, rapid, accurate and low-cost analysis of all elements in the periodic table. Regardless of the physical state of the sample, the technique can be applied to the analysis of solid, liquid, and gaseous samples and therefore finds large-scale application area from environmental to nuclear sciences. However, due to some experimental challenges in direct liquid analysis by LIBS, significant amount of work in the literature is based on the method development studies for converting the sample matrix from liquid to solid phase. Approaches like; freezing into ice [3], use of several adsorbent materials like filter paper [4,5], graphite [6], wood slices [7] and calcium hydroxide pellets [8], utilization of ionexchange [9,10] and PVC membranes [11], solidification techniques based on formation of hydro gels [12] and cross-linked PVA polymer film [13], enrichment by electro deposition $[14,15]$ and various preconcentration techniques [16-19] and deposition of silver and gold nanoparticles on the sample surface (NELIBS) [20] provide element and substrate-specific enhancements in signal intensities and hence, improvements up to orders of magnitude in detection limits are reported.
Dried-droplet analysis [21] is another alternative strategy in liquids analysis by LIBS. The methodology consisted of loading, drying and analyzing steps. Some volumes of aqueous metal solutions are placed on the substrate, either directly or after several enrichment procedures applied. After a few minutes of drying at room temperature, energetic laser pulses are used to form plasma on the dry residue. The analysis of luminous plasma emission reveals both qualitative and quantitative information about the elements present in droplet residue. The intensity of the LIBS signal observed is related with the amount of the analyte as well as the type of the substrate onto which the droplet is loaded. Laser spectroscopic analysis of micro-droplets on metallic substrates and substrate-laser interactions are investigated under the subject of surface-enhanced LIBS, i.e., SENLIBS. The work by Aguirre et al. [17], one of the pioneering study performed on SENLIBS, reports improvements in sensitivity, precision and linearity of the calibration curve for some elements on metallic aluminum substrate compared to direct analysis of micro droplets. 50-fold enhancement in Mn signal and $6 \mu$ g. $g^{-1}$ LOD for Mn on a metallic aluminum substrate is reported. Another study based on the use of metallic aluminum substrate by Zheng et al. [22] investigates matrix effect in chlorine analysis by LIBS for the samples prepared with different mineral salts in the forms of pellet or in a dried

\footnotetext{
* Corresponding author.

E-mail address: serifeyalcin@iyte.edu.tr (Ş. Yalçın).
} 
solution layer on a metallic aluminum target. A negligible matrix effect for dried liquid samples has been observed compared to the pelletized solid samples. Simultaneous determination of the rare earth elements (REEs), La, Ce, Pr, and Nd, in aqueous solution using surface-enhanced laser-induced breakdown spectroscopy on a Zn metal substrate have been carried out by Yang et al. [23]. The LODs were at the level of 0.85 , 4.07, 2.97 and $10.98 \mu \mathrm{g} \cdot \mathrm{ml}^{-1}$ for La, Ce, Pr and Nd, respectively. Authors indicate 2-4 times enhancements with the use of $\mathrm{Zn}$ metal substrate compared to the results obtained with the use of filter paper as a substrate.

Surface properties of the substrate have some important roles on the analytical performance of SENLIBS technique. One of the drawbacks of using polished substrates in the dried-droplet analysis by LIBS is the uncontrollable distribution of the analyte droplets on the substrate material during drying process. This results with a loss in reproducibility and worse analytical figures of merits. Pre-treatment of the substrate surfaces, silicon wafer [24] and polished aluminum [25], by laser patterning provides some advantages like trapping the analyte solution in a well-defined area with homogeneous distribution and hence improvements in sensitivity and detection limits may obtained.

Several SENLIBS studies in the literature are based on the use of metallic substrates ( $\mathrm{Al}, \mathrm{Mg}$, $\mathrm{Zn}$, etc.) in which most of the laser energy is absorbed by the metallic surface and transferred to the analyte. However, studies based on the use of non-metallic substrates on LIBS signal intensity are not many. For the last few years in our group, we are developing methods and investigating the performance and capabilities of laser-induced breakdown spectroscopy for dried-droplet analysis by using non-metallic substrates. We have previously shown [21] that, $300 \mathrm{~nm}$ oxide-coated silicon wafer $\left(\mathrm{Si}+\mathrm{SiO}_{2}\right)$ has an excellent potential to be used as a substrate for dried-droplet analysis. With high energy laser pulses focused on the sample surface, outside the minimum focal point condition, $\mathrm{Cu}$ (I) signal at $324.75 \mathrm{~nm}$ indicated more than 7 times enhancement in $\mathrm{S} / \mathrm{N}$ compared to the one obtained at the minimum focus condition experiments. With the use of $300 \mathrm{~nm}$ oxide-coated silicon wafer substrate, several picograms of absolute detection limits for $\mathrm{Cu}, \mathrm{Cd}, \mathrm{Mn}$ and $\mathrm{Pb}$ were obtained. Here, in this paper, a comparative study based on the use of bare crystalline silicon (c-Si), and two coated silicon wafer substrates: $300 \mathrm{~nm}$ oxide-coated silicon wafer $\left(\mathrm{SiO}_{2+} \mathrm{Si}\right)$, and $300 \mathrm{~nm}$ nitride-coated silicon wafer $\left(\mathrm{Si}_{3} \mathrm{~N}_{4}+\mathrm{Si}\right)$, for dried-droplet analysis is presented with emphasis on signal enhancement and improvement in detection limits of $\mathrm{Cd}, \mathrm{Cr}, \mathrm{Cu}$, $\mathrm{Mn}$ and $\mathrm{Pb}$ elements. It has been observed that nitride-coated silicon substrate exhibited strong enhancements in signal intensity, for most emission lines of the analyte species, compared to other silicon wafer based substrates. The methodology presented is fast, simple and accurate for direct analysis of aqueous samples for environmental monitoring purposes and also has a potential to be applied to the analysis of biological samples where the sample size is limited. Main findings regarding the factors that influence the analytical capability of the LIBS technique in dried-droplet analysis are presented.

\section{Experimental}

\subsection{Instrumentation}

An experimental LIBS set-up constructed from its commercially available parts is schematically shown in Fig. 1. A Q-switched Nd:YAG laser source (Quanta-Ray Lab-170, Spectra Physics, California- USA) with $10 \mathrm{~ns}$ duration time has been operated at its second harmonic wavelength, $532 \mathrm{~nm}$. The laser beam is directed on the target by reflective mirrors and is focused onto the sample surface by a $17.5 \mathrm{~cm}$ focal length plano-convex lens placed at a position $15 \mathrm{~cm}$ away from the sample. At this condition, the laser beam was $1.3 \mathrm{~mm}$ in diameter (with irradiance value of $\sim 1.15 \mathrm{GW} / \mathrm{cm}^{2}$ ) and large enough to cover the entire droplet area for ablation from a single laser pulse. Laser pulse energy is measured by a power meter (PE50BB-DIF-V2, Nova II, Ophir).

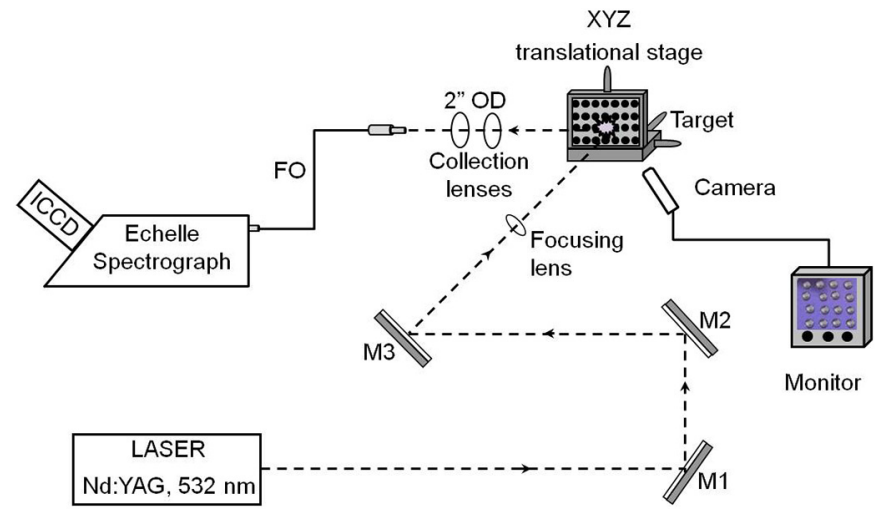

Fig. 1. Experimental LIBS set-up. M1, M2 and M3: reflecting mirrors, FO: fiber optic cable, ICCD: Intensified Charge Coupled Detector.

A fiber optic cable with $450 \mu \mathrm{m}$ core diameter was used to carry plasma emission onto the entrance slit of an echelle spectrograph (Mechelle 5000, Andor Inc.) equipped with an intensified charged coupled device (ICCD) (iStar DH734, Andor Inc.).

The spectrograph and detection system spectral range is between 200 and $850 \mathrm{~nm}$ with $0.08 \mathrm{~nm}$ resolution at $400 \mathrm{~nm}$. An XY-translational stage is used to provide fresh spots during sampling. The sampling position on the substrate with respect to the laser beam was monitored by a camera system. A UV-Vis-NIR spectrometer (PerkinElmer, Lambda 950) with reflectance attachment was used for reflectance measurements.

\subsection{Materials and methods}

Three types of silicon wafer based substrates: crystalline silicon wafer (c-Si), thermally oxidized silicon wafer with $300 \mathrm{~nm}$ oxide layer on c-Si $\left(\mathrm{SiO}_{2}+\mathrm{Si}\right)$, and $300 \mathrm{~nm}$ silicon nitride layer on c-Silicon wafer substrate $\left(\mathrm{Si}_{3} \mathrm{~N}_{4}+\mathrm{Si}\right.$ ), were used without treatment (Nanografi Inc.). Single element calibration standards were prepared from their stock solutions by serial dilutions with ultrapure water. $500 \mathrm{~nL}$ sample solutions were loaded onto the substrate with a micropipette dispenser and let dry at room temperature, in ambient atmosphere. The approximate time to dry $500 \mathrm{~nL}$ volume of a droplet is about $5 \mathrm{~min}$. After liquid to solid conversion process is completed, the solid residue on the substrate is analyzed by LIBS. The experimental conditions like; laser pulse energy, detector delay time and detector gate time were optimized in order to maximize the signal for each element. These optimization studies are common practices in LIBS measurements, therefore, without presenting the detailed results only the optimum experimental conditions used throughout the experiments are listed in Table 1. below.

\section{Results and discussion}

Three different silicon wafer based substrates were comparatively investigated for dried-droplet analysis of $\mathrm{Cd}, \mathrm{Cr}, \mathrm{Cu}, \mathrm{Mn}$, and $\mathrm{Pb}$ elements by LIBS, with emphasis on signal enhancement and detection

Table 1

Transition probability, $A_{k i}$, and optimum experimental conditions for the spectral lines of interest. $T_{\mathrm{d}}$ : detector delay time, $\mathrm{T}_{\mathrm{g}}$ : detector gate time.

\begin{tabular}{lllll}
\hline Element & Wavelength $(\mathrm{nm})$ & $\mathrm{A}_{\mathrm{ki}^{*}}{ }^{*}\left(\mathrm{~s}^{-1}\right)$ & $\mathrm{t}_{\mathrm{d}}(\mu \mathrm{s})$ & $\mathrm{t}_{\mathrm{g}}(\mu \mathrm{s})$ \\
\hline $\mathrm{Cd}(\mathrm{I})$ & 508.58 & $5.6 \times 10^{7}$ & 0.75 & 500 \\
$\mathrm{Cu}(\mathrm{I})$ & 324.75 & $1.4 \times 10^{8}$ & 1.75 & 500 \\
$\mathrm{Cr}(\mathrm{I})$ & 360.53 & $1.6 \times 10^{8}$ & 1.50 & 250 \\
$\mathrm{Mn}(\mathrm{I})$ & 403.08 & $1.7 \times 10^{7}$ & 1.00 & 750 \\
$\mathrm{~Pb}(\mathrm{I})$ & 405.78 & $9.0 \times 10^{7}$ & 2.00 & 500 \\
\hline
\end{tabular}

* https://physics.nist.gov/PhysRefData/ASD/lines_form.html 


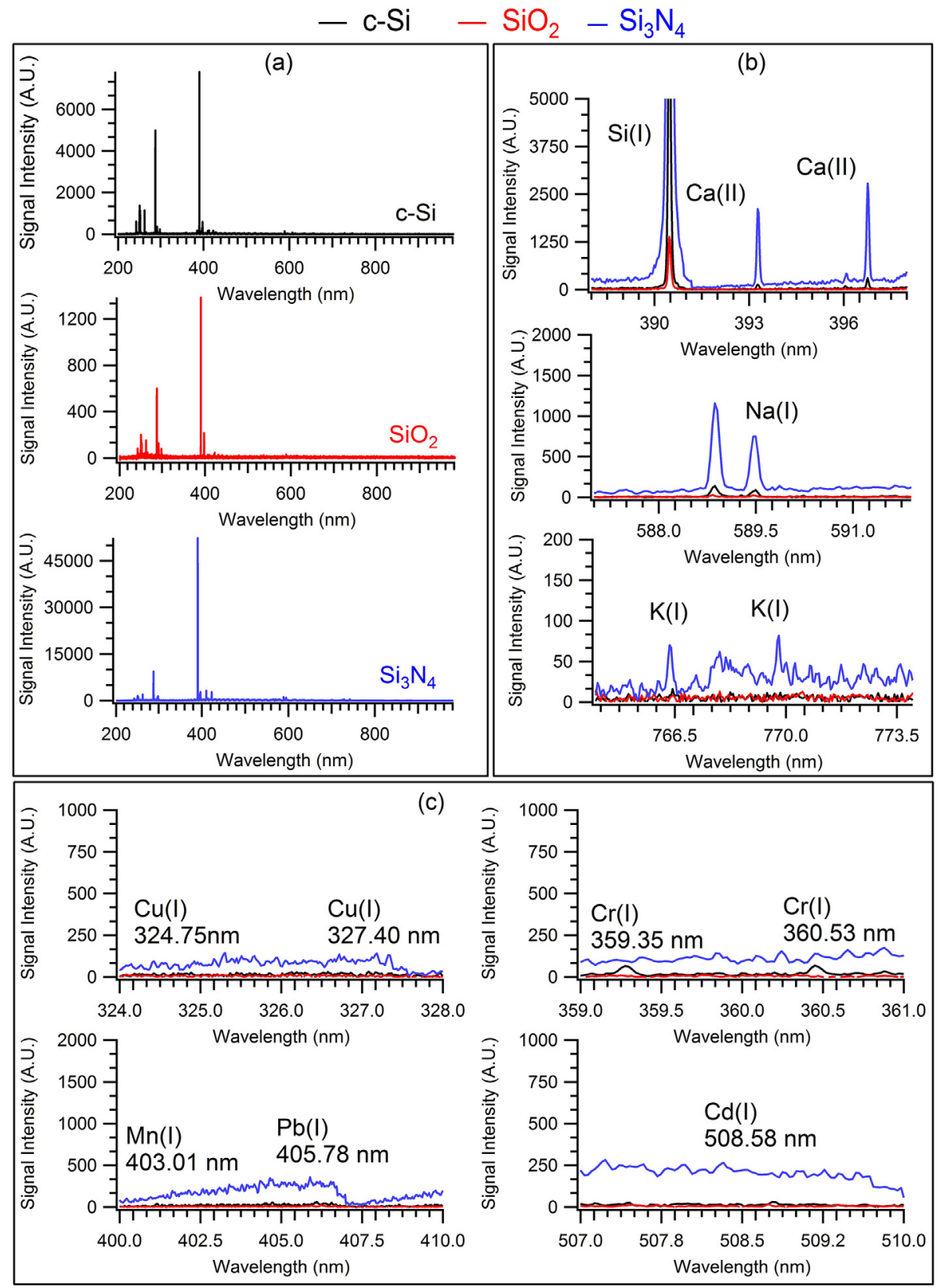

Fig. 2. (a) Full spectra of the blank substrates. Enlarged viewing of the regions where (b) matrix emissions and (c) analyte emissions are observed. Data are obtained with $110 \mathrm{~mJ}$ laser pulse energy and are from the average of the first shots of five separate droplets.

limit determination. Various factors that are thought to be responsible for the enhanced performance of nitride-coated silicon wafer substrates were studied.

\subsection{Representative LIBS spectra of the silicon wafer based substrates}

In dried-droplet analysis, it is essential that the substrate be free from the elemental emission lines that may overlap with the analyte emission. In order to identify the absence of spectral interference from the three silicon wafer based substrates, a series of measurements were performed on blank substrates, for the most prominent emission lines of $\mathrm{Cd}, \mathrm{Cr}, \mathrm{Cu}, \mathrm{Mn}$ and $\mathrm{Pb}$. Full LIBS spectra $(200-900 \mathrm{~nm})$ of the three blank substrates obtained with $110 \mathrm{~mJ}$ laser pulse energy are shown in Fig. 2(a). It can be seen that the elemental lines observed are almost the same for the three substrates (mainly neutral and ionic emission lines of silicon, oxygen, and nitrogen) but the signal strength varies from one to another. The relative magnitude of the signal intensities in Fig. 2(a) clearly indicates that the response exhibited by $\mathrm{Si}_{3} \mathrm{~N}_{4}$ coated substrate is the highest among the three. Overlay spectra of the three substrates for different spectral regions of the full spectrum are also given in Fig. 2(b) and in Fig. 2(c), enlarged. Fig. 2(b) represents spectral regions where some emission lines of matrix elements ( $\mathrm{Si}, \mathrm{Na}, \mathrm{K}$ and $\mathrm{Ca}$ ) appear. Signal intensity from the most prominent emission lines of these elements is the highest with $\mathrm{Si}_{3} \mathrm{~N}_{4}$ coated substrate, compared to the ones from the other silicon based substrates. Undetectable potassium (at $766.49 \mathrm{~nm}$ and $769.89 \mathrm{~nm}$ ), and barely visible calcium (at $393.36 \mathrm{~nm}$ and $396.84 \mathrm{~nm}$ ) lines in c-Si and oxide-coated substrates could easily be identified on $\mathrm{Si}_{3} \mathrm{~N}_{4}$ substrate. Similarly, for $\mathrm{Si}(\mathrm{I}) 390.46 \mathrm{~nm}$ and $\mathrm{Na}(\mathrm{I})$ $589.0 \mathrm{~nm}$ line emissions, 20 and 30 times enhancements were observed on $\mathrm{Si}_{3} \mathrm{~N}_{4}$ coated substrate compared to that of c-Si type. Overlay spectra of the three substrates in the region where analyte emission lines observed are presented in Fig. 2(c). No signal that can be associated with the $\mathrm{Cd}, \mathrm{Cr}, \mathrm{Cu}, \mathrm{Mn}$, and $\mathrm{Pb}$ emission lines are observed, for all substrates. This clearly indicates the absence of spectral interference in the 


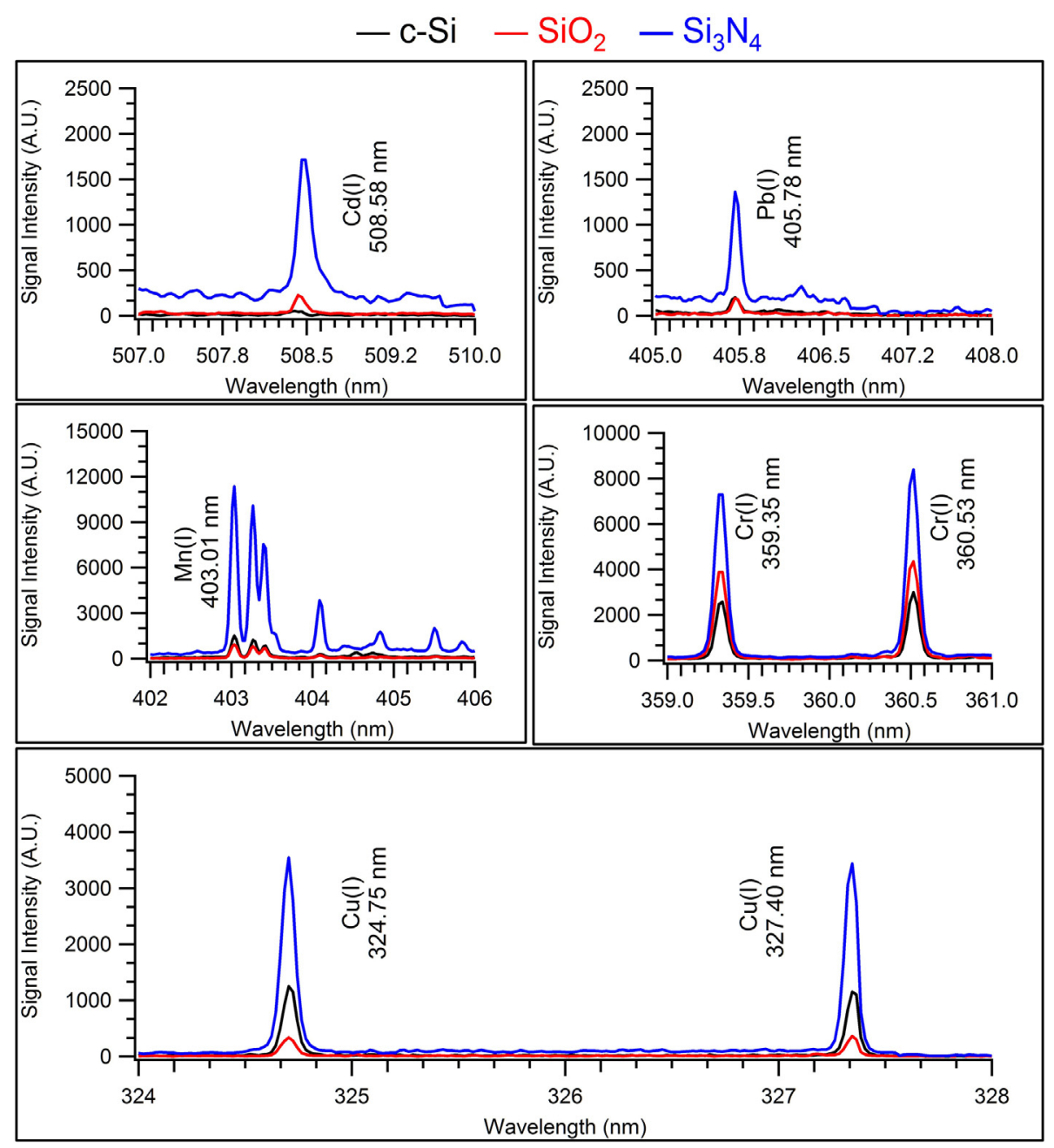

Fig. 3. LIBS spectral regions representing the most prominent emission lines of $\mathrm{Cd}(\mathrm{I}), \mathrm{Pb}(\mathrm{I}), \mathrm{Mn}(\mathrm{I}), \mathrm{Cr}(\mathrm{I})$ and $\mathrm{Cu}(\mathrm{I})$, on the three silicon wafer based substrates. Analyte concentrations of $1 \mathrm{mg} \mathrm{L}^{-1}$ and laser pulse energy of $110 \mathrm{~mJ}$ were used under the optimum experimental settings.

use of silicon wafer based substrates for dried-droplet analysis of the considered elements. The enhanced sensitivity of the $\mathrm{Si}_{3} \mathrm{~N}_{4}$ surface over other types of substrates is also apparent from the higher background levels observed within the spectral range of interest. Data are the average of the signals from the first laser shots of five separate droplets, under optimum experimental conditions.

\subsection{The substrate effect on analyte intensity}

The surface enhancement effect was investigated by LIBS analysis of dried-droplets on the three silicon wafer based substrates. For that purpose, $500 \mathrm{~nL}, 1 \mathrm{mg} \mathrm{L}^{-1}$ standard analyte solutions, (Cd, Cr, Cu, Mn and $\mathrm{Pb}$ ), were loaded onto the substrates, dried and subjected to $110 \mathrm{~mJ}$ laser pulses for plasma formation. Fig. 3. shows overlay spectra of the three substrates, for each element, representing their relative signal strength. Data are the average of the signals from the first laser pulse of five separate droplets.

As it can be seen from the Fig. 3 that, $\mathrm{Si}_{3} \mathrm{~N}_{4}$ coated substrate exhibited the highest sensitivity for all the elements studied, in terms of both analyte and background signal. Therefore, peak profiles are quantified after background subtraction, and the enhancement factors obtained for $\mathrm{Si}_{3} \mathrm{~N}_{4}$ substrate with respect to $\mathrm{SiO}_{2}$ and c-Si substrate for the most prominent emission lines of all the elements are listed in Table 2. In this table, enhancement factors for $\mathrm{Si}_{3} \mathrm{~N}_{4}$ substrate with respect to $\mathrm{SiO}_{2}$ substrate are considered more meaningful than that of for $\mathrm{Si}_{3} \mathrm{~N}_{4}$ with respect to c-Si ones, for the reason that the coated
Table 2

Signal enhancement factors observed on $\mathrm{Si}_{3} \mathrm{~N}_{4}$ substrate with respect to $\mathrm{SiO}_{2}$ and c-Si substrate, for the prominent emission lines of the elements studied.

\begin{tabular}{lll}
\hline Analyte & \multicolumn{2}{c}{ Enhancement factors for $\mathrm{Si}_{3} \mathrm{~N}_{4}$ substrate with respect to } \\
\cline { 2 - 3 } & $\mathrm{SiO} 2$ & $\mathrm{c}-\mathrm{Si}$ \\
\hline $\mathrm{Cd}(\mathrm{I}) 508.58 \mathrm{~nm}$ & 11 & 62 \\
$\mathrm{Cr}(\mathrm{I}) 360.53 \mathrm{~nm}$ & 2 & 3 \\
$\mathrm{Cr}(\mathrm{I}) 359.35 \mathrm{~nm}$ & 2 & 3 \\
$\mathrm{Cu}(\mathrm{I}) 327.4 \mathrm{~nm}$ & 10 & 3 \\
$\mathrm{Cu}(\mathrm{I}) 324.7 \mathrm{~nm}$ & 11 & 3 \\
$\mathrm{Mn}(\mathrm{I}) 403.08 \mathrm{~nm}$ & 12 & 8 \\
$\mathrm{~Pb}(\mathrm{I}) 405.78 \mathrm{~nm}$ & 6 & 7 \\
\hline
\end{tabular}

* $1 \mathrm{mg} \mathrm{L}^{-1}$ standard analyte solutions were used.

substrates response to intense laser radiation occur mainly due to the surface properties rather than bulk properties as in the case of c-Si. From surface to bulk, different thermal mechanisms and heat transport phenomenon inside the material is expected

Enhancement factors vary from one element to another as signal intensity depends on several factors other than the substrate itself; however, analyte signal observed on $\mathrm{Si}_{3} \mathrm{~N}_{4}$ coated substrate is always higher than the ones from the other two substrates. Minimum enhancement factors are observed for the chromium lines, $\operatorname{Cr}(\mathrm{I}) 359.35$ and $360.53 \mathrm{~nm}$, where signal strength observed on $\mathrm{Si}_{3} \mathrm{~N}_{4}$ coated substrate is almost two and three times more than the ones on $\mathrm{SiO}_{2}$ and c-Si 
substrates, respectively. $\mathrm{Si}_{3} \mathrm{~N}_{4}$ substrate showed enhancements more than 6 times for $\mathrm{Pb}$, and more than 10 times for $\mathrm{Cu}, \mathrm{Mn}$ and $\mathrm{Cd}$, with respect to the ones obtained with $\mathrm{SiO}_{2}$ substrate. Also, for $\mathrm{Cd}(\mathrm{I})$ $508.58 \mathrm{~nm}$ emission line, more than 62 and 11 times enhancements were obtained compared to those of c-Si and $\mathrm{SiO}_{2}$ substrates, respectively. This enhancement factor of 62 for Cd with respect to c-Si substrate may be overestimated because Cd signal is too small and barely resolved from the background signal. While the general trend of observation of highest signal intensity on $\mathrm{Si}_{3} \mathrm{~N}_{4}$ surfaces is always the case, the comparative ratio order between the two substrate, (c-Si and $\mathrm{SiO} 2$ ) was changing with different analyte.

Silicon nitride ceramics has been extensively studied in high temperature applications due to its superior thermo-mechanical properties like high temperature strength, good thermal shock resistance, wear resistance, fracture toughness and good oxidation resistance [26]. Due to their wide band gap, $(5.0 \mathrm{eV})$, silicon nitride thin-films $[26,27]$ on semiconductors are commonly employed for anti-reflection and passivation coatings for crystalline-silicon solar cells. Also, silicon nitridebased plasmonic waveguides, $\mathrm{Cu}-\mathrm{SiO}_{2}-\mathrm{Si}_{3} \mathrm{~N}_{4}-\mathrm{SiO}_{2}-\mathrm{Cu}$ and $\mathrm{Cu}-\mathrm{Si}_{3} \mathrm{~N}_{4}-\mathrm{Cu}$, has been experimentally demonstrated [28]. In order to better understand the signal enhancement effect observed on silicon nitride-coated surfaces, reflectance measurements and SEM based surface characterization measurements were performed.

\subsubsection{Reflectivity measurements}

Reflection is the fraction of light reflected from a surface as a function of wavelength. According to the well known conservation law, when a radiation of wavelength $(\lambda)$ strikes a boundary between two media, a portion of the wave is reflected (R), a portion is absorbed (A), and a portion is transmitted (T) into the medium. A quantitative statement of the conservation law can be written as; $A(\lambda)+R$ $((\lambda)+\mathrm{T}((\lambda)=1$. With opaque surfaces, where transmission is not significant, reflectance and absorbance varies in proportion. The reflectance data for the three Si-wafer based substrates (between 450 and $650 \mathrm{~nm}$ ranges) is shown in Fig. 4.

At the wavelength of $532 \mathrm{~nm}$, which is the wavelength of the laser used for plasma formation, $\mathrm{Si}_{3} \mathrm{~N}_{4}$ coated surface exhibits the lowest reflectance value of $2 \%$, compared to $17 \%$ of $\mathrm{SiO}_{2}$ and $45 \%$ of c-Si surfaces. Considering highly absorptive behavior of the nitride coated surface to $532 \mathrm{~nm}$ laser light, one can think of that this absorbed energy could be transferred to the analyte for more efficient atomization and excitation of the analyte compared to other silicon based substrates, and hence the observed enhancement affect may be associated with the reflectivity. While this may be true in part, however, without taking into consideration of the thermal effects under intense laser radiation, a direct relationship between the signal enhancement and the reflectivity

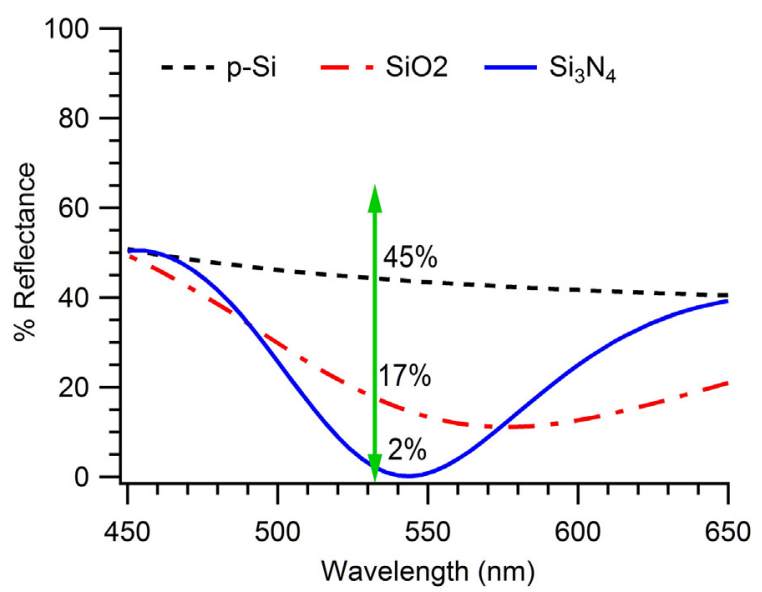

Fig. 4. Reflectance spectra of the silicon wafer based substrates in the region of interest. of the substrate cannot be generalized.

In laser ablation of dielectric surfaces, when incident laser beam energy exceeds the evaporation temperature of the substrate $(2150 \mathrm{~K}$ for $\mathrm{Si}_{3} \mathrm{~N}_{4}, 1600$ for $\mathrm{SiO} 2$ and 1415 for $\mathrm{c}-\mathrm{Si}$ ), the heat created by the strong absorption of intense laser radiation causes rapid heating of the surface that could result in phase transition from solid to vapor without melting, as is mentioned in several articles in the literature [29,30]. This phase transition mechanism due to rapid heating of the substrate material may help readily transfer of the analyte for more efficient vaporization, atomization and excitation. Additionally, when the three substrates are considered, the decomposition products during this phase transition are different. $\mathrm{Si}_{3} \mathrm{~N}_{4}$ decompose into gaseous nitrogen and liquid silicon [31], producing an inert nitrogen atmosphere which may facilitate the signal enhancement of the analyte atoms. On the other hand, reactive and oxidative oxygen gas produced from the decomposition of $\mathrm{SiO}_{2}$ can significantly change the plasma characteristics.

It is also known that energy absorption by solids occur within the optical absorption depth of the material and for most semiconductors and insulators the optical absorption depth is longer (around micrometers range), compared to that of metals (around $10 \mathrm{~nm}$ ) [32]. Therefore, considering microns range of absorption depths of the materials used in this study and $300 \mathrm{~nm}$ nitride/oxide coatings over bare silicon wafer, the interaction of the laser is not only confined to the surface without altering the bulk. Some thermal modifications are expected. When thermal conductivity values [32] (at $300 \mathrm{~K}$ ) of the substrates are considered, $150,1.4$ and $30 \mathrm{~W} \cdot \mathrm{m}^{-1} \cdot \mathrm{K}^{-1}$ for $\mathrm{c}-\mathrm{Si}, \mathrm{SiO}_{2}$ and $\mathrm{Si}_{3} \mathrm{~N}_{4}$, respectively, a thermal conductivity difference between $\mathrm{SiO}_{2}$ and the silicon wafer beneath, is larger than that of $\mathrm{Si}_{3} \mathrm{~N}_{4}$ and silicon wafer. This large difference may have an impact on the heat transfer and thermalization time, which may be associated with the rapid heating mechanism favored in $\mathrm{Si}_{3} \mathrm{~N}_{4}$ coated surface.

\subsubsection{Surface morphology of the substrates}

In order to understand if the enhancement effect observed is due to the presence of nanoparticles formation on dried droplets, which may lead to the enhancement of the local electric field under intense laser radiation and hence enhanced ejection of electrons like in the case of NELIBS, surface characterization of the droplets were performed. SEM pictures of dried droplets (a-c), and laser ablated craters (d-f) on three different silicon-wafer based substrates are given in Fig. 5. Irregular/ non-uniform shapes of the dried droplets on three different substrates, as is seen in Fig. 5(a-c), with differing phase segregation behaviors are observed. Besides, enlarged viewing from different regions of the droplets given in Fig. 5(a), is presented in Fig. 5(g-h). It is clearly observed that crystal formation with several microns large particle sizes due to agglomeration occurs. Therefore, the signal enhancement effect observed in this study may not be ascribed to nanoparticles formation on dried droplets. On the other hand, SEM pictures of laser ablated craters on three different substrates, c-Si, $\mathrm{SiO}_{2}$ and $\mathrm{Si}_{3} \mathrm{~N}_{4}$, shown in Fig. 5(d-f), respectively, indicate differences in the extent of the damage and the ablation characteristics. For the c-Si one, substrate melting with some mechanical cracking and more material deposition around the crater compared to other two substrates are observed, Fig. 5(d). However, the craters on silicon oxide and nitride coated substrates, Fig. 5(e-f), have more smooth appearance and more homogenous ablation with less debris around, compared to c-Si one. This observation may provide a supporting evidence for the occurrence of phase transition without melting as is mentioned in the previous section.

\subsection{Single pulse versus multiple pulse analysis}

Laser-Induced Breakdown Spectroscopic analysis of solid samples at a specific location is usually performed by single or sequential multiple laser pulses focused on the same spot. Despite some disadvantages, like shot-to-shot variations in the laser source and hence poor reproducibility, single-shot LIBS technique [33] offers rapid chemical analysis 


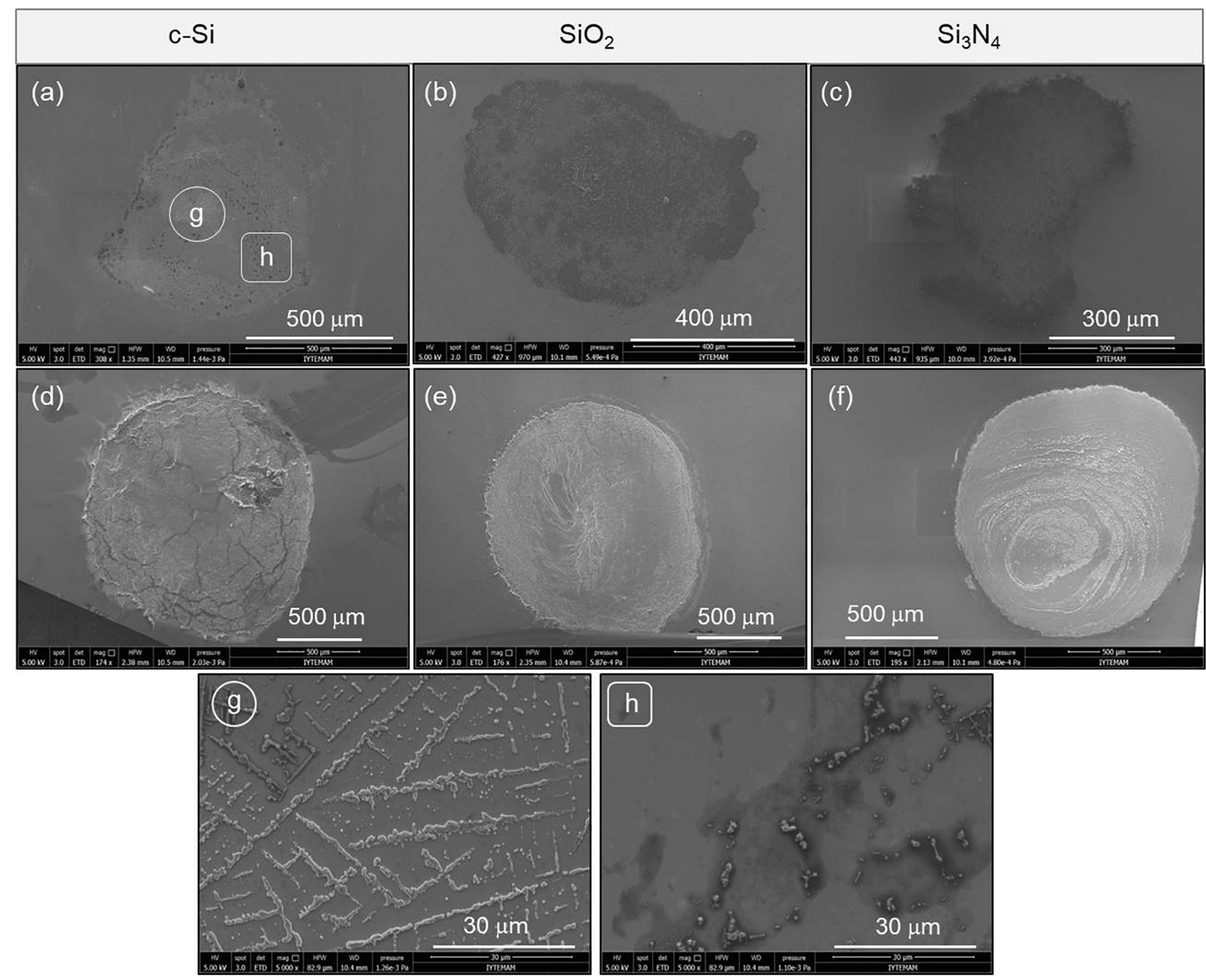

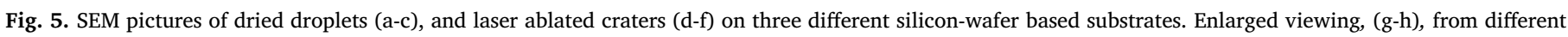
regions of the droplet (a), shows crystal formation due to agglomeration of large size particles.

and less destructive measurements. In addition, single shot analysis allows constructing surface topography through 2-D mapping. In this study, the potential use of single laser pulses for dried-droplet analysis in terms of the complete removal of the analyte residue from the substrate surface within the first laser pulse has been investigated. The signal intensity variations of $\mathrm{Pb}, \mathrm{Cu}, \mathrm{Mn}$ and $\mathrm{Na}$ elements with respect to sequential laser pulses, on three silicon wafer based substrates, are given in Fig. 6. In general, most of the analyte signal is recorded within the first laser pulse when $\mathrm{Si}_{3} \mathrm{~N}_{4}$ coated substrate is used. Also, some signal could also be observed from the subsequent laser pulses when $\mathrm{SiO}_{2}$ and c-Si type substrates are used. As is shown in Fig. 6, more than $99 \%$ of the $\mathrm{Pb}(\mathrm{I})$ signal is extracted within the first laser pulse, with the $\mathrm{Si}_{3} \mathrm{~N}_{4}$ coated substrate, whereas $95 \%$ and $63 \%$ of the $\mathrm{Pb}$ signal is observed with $\mathrm{SiO}_{2}$ and c-Si type substrates, respectively. These results support the idea that $\mathrm{Si}_{3} \mathrm{~N}_{4}$ surface is highly absorptive and more efficient in energy transfer to the analyte, compared to other silicon wafer based substrates and favors the use of nitride-coated substrates in LIBS analysis of aqueous metal solutions.

\subsection{Analytical performance of the technique}

In order to evaluate the analytical performance of the silicon wafer based substrates for dried-droplet analysis by LIBS, calibration curves were constructed, and LOD values were calculated. The applicability of the methodology to real water samples and determination of performance parameters (accuracy and precision) was tested on the certified reference water sample, CRM-TMDW and ICP multi-element standard sample, ICP-MES. Data on calibration curves represent the average signal from five single laser shots, each on different droplet residue. In each sampling, laser spot size was big enough to cover the whole droplet area for ablation. The area under selected analytical lines of $\mathrm{Cd}, \mathrm{Cr}$, $\mathrm{Cu}, \mathrm{Mn}$ and $\mathrm{Pb}$ elements were quantified after baseline subtraction. As is seen in Fig. 7, the calibration curves are linear with minimum regression constant of 0.96 over a range of concentrations from $1 \mathrm{ng} \mathrm{mL}^{-1}$ (ppb) to $8 \mu \mathrm{g} \mathrm{mL}{ }^{-1}$ (ppm).

The slopes of the calibration curves were utilized to calculate the limit of detection, LOD, based on the IUPAC definition with $95 \%$ confidence limit, $\mathrm{LOD}=3 \sigma_{\mathrm{BG}} / \mathrm{m}$, where $\sigma_{\mathrm{BG}}$ is the standard deviation of the background and $\mathrm{m}$ is the slope of the calibration curve. Repeatability of the measurements, calculated as relative standard deviation, RSD, for 5 replicate measurements were shown as error bars in each graph. Table 3. below, lists absolute LOD values for nitride substrate and concentration based LOD values calculated from the slopes of the calibration graphs, for each element and each substrate. Also, some 


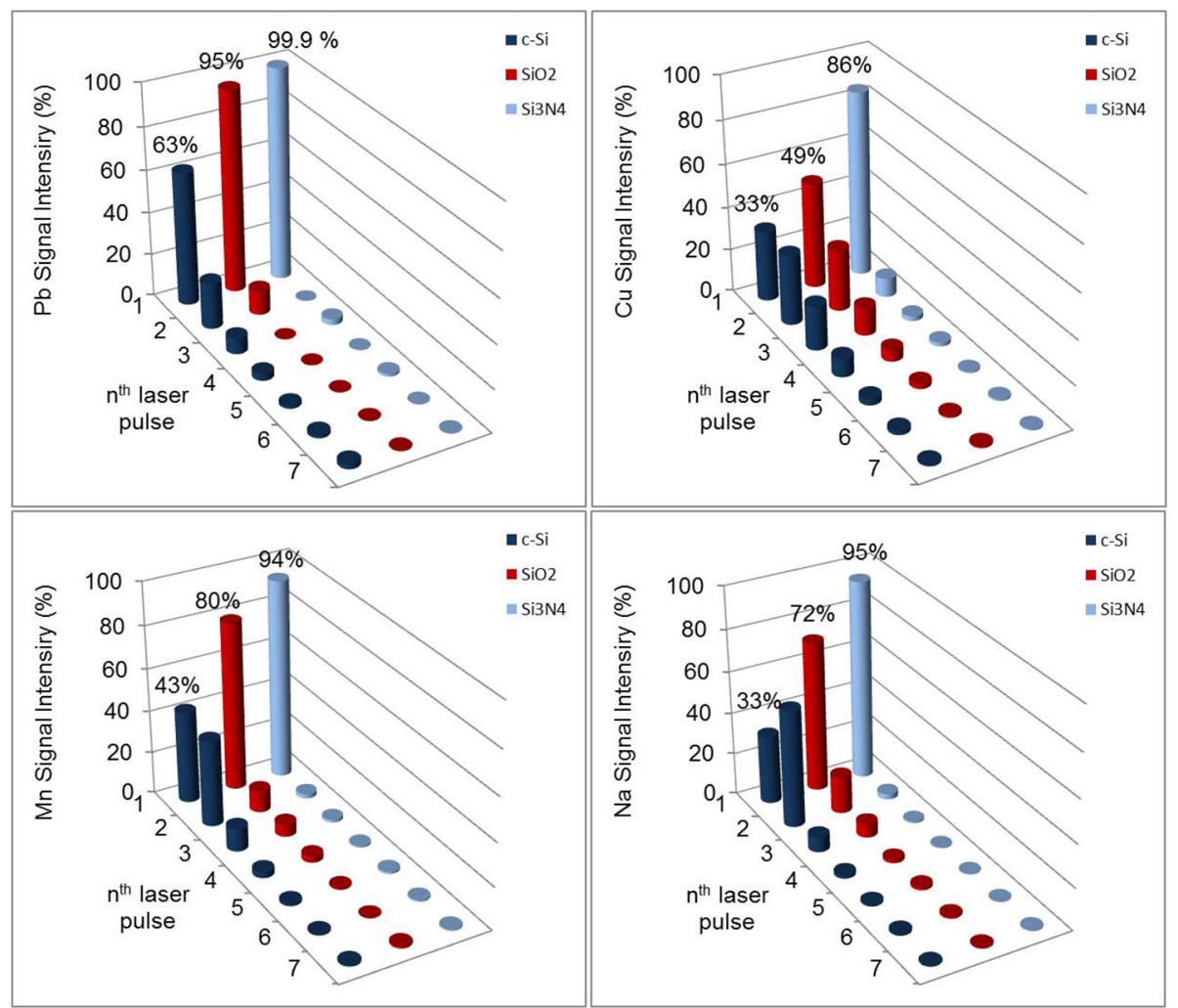

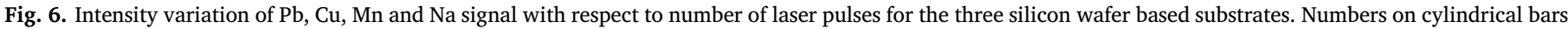
indicate the percentage signal observed within the first laser pulse.

LOD values from the literature that make use of the similar methodology were included in the last column, for comparison purposes.

According to data presented in Table 3, among the three substrates, for all the elements, the lowest LOD values were obtained from the silicon nitride-coated one. These LOD values correspond to detection of $0.5 \mathrm{pg} \mathrm{Cu}, 1.5 \mathrm{pg} \mathrm{Cr}, 2 \mathrm{pg} \mathrm{Mn}, 11 \mathrm{pg} \mathrm{Pb}$ and $62 \mathrm{pg} \mathrm{Cd}$ in absolute amounts, for a single loading of $500 \mathrm{~nL}$ analyte solution. LOD values obtained for $\mathrm{Cu}, \mathrm{Cr}$ and $\mathrm{Mn}$ are below the minimum contaminant regulations for environmental purposes and it shows great potential that any of these silicon wafer based substrates may be used for dried-droplet analysis of $\mathrm{Cu}, \mathrm{Cr}$ and $\mathrm{Mn}$ in drinking water. In the current situation, the proposed technique is not capable of analyzing $\mathrm{Pb}$ and $\mathrm{Cd}$ in drinking water, but may be well suited for the analysis of these elements in waste-water for quality monitoring purposes. In addition, use of larger volumes or sequential loading and drying of the analyte solution on the same spot could enrich the analyte and hence may facilitate the detection of $\mathrm{Cd}$ and $\mathrm{Pb}$ at lower concentrations. When we compare our results with the literature, the most recent study [25] is based on the use of laser-pretreated metallic Al-target for liquids analysis. After enrichment, by repetitive deposition and drying steps, an LOD value of $184 \mathrm{ppb}$ is reported for Cd. This result, based on the use of $20 \mathrm{~mL}$ of liquid sample in the enrichment process with the help of a hotplate, is time consuming, prone to contamination and still higher than the LOD values obtained in our study. In comparison, for a single loading of $500 \mathrm{~nL} \mathrm{Cd}$ solution, LOD values of $151 \mathrm{ng} \mathrm{mL}^{-1}$ and $124 \mathrm{ng} \mathrm{mL}^{-1}$ were obtained from $\mathrm{SiO}_{2}$ and $\mathrm{Si}_{3} \mathrm{~N}_{4}$ coated substrates, respectively.

Chromium was also studied by the same group. The LOD values of $4 \mathrm{ng} \mathrm{mL}{ }^{-1}$ and $3 \mathrm{ng} \mathrm{mL}^{-1} \mathrm{Cr}$ obtained in our study, with the use of $\mathrm{SiO}_{2}$ and $\mathrm{Si}_{3} \mathrm{~N}_{4}$ coated substrate, respectively, are almost five and seven times lower than the one reported [25], as $19 \mathrm{ng} \mathrm{mL}^{-1} \mathrm{Cr}$. Also, according to the information provided in the same article, the approximate irradiance value (estimated as $10 \mathrm{GW} / \mathrm{cm}^{2}$ ) is higher than the one used in our study. An LOD value of $3.1 \mu \mathrm{g} \mathrm{kg}^{-1} \mathrm{Cr}$ reported by Gaubeur et.al [16]., based on the use of dispersive liquid-liquid micro-extraction procedure followed by laser-induced breakdown spectrometry detection, (DLLME-LIBS), is close to LOD values presented in our study, however, an LOD value of $6 \mu \mathrm{g} . \mathrm{g}^{-1} \mathrm{Mn}$ on metallic aluminum substrate reported by Aguirre et al. [17], is about 3 orders of magnitude higher than the ones presented in this study.

Another study related to our work is based on the use of magnesium alloy surface for chemical replacement combined with SENLIBS methodology [18]. Authors report LOD's of 420, 25, 250, and $118 \mathrm{ng} \mathrm{mL} \mathrm{mL}^{-1}$ for $\mathrm{Cd}, \mathrm{Cr}, \mathrm{Cu}$ and $\mathrm{Pb}$, respectively. Compared to our results presented in Table 3., these values are all higher for all the elements studied; almost an order of magnitude higher for $\mathrm{Cr}$ and more than 2 orders of magnitude higher for $\mathrm{Cu}$, when $\mathrm{Si}_{3} \mathrm{~N}_{4}$ substrate is considered.

In order to evaluate the performance characteristics (accuracy and precision) of the substrates for dried-droplet analysis of liquid samples, the certified reference water sample, CRM-TMDW and ICP multi-element standard sample, ICP-MES, were utilized. The accuracy of an analytical procedure is given by the closeness of the analysis results (determined value) to the true (certified) value and generally reported in terms of percent error. Percent error of the measurements calculated from the use of certified and determined values for the three substrates are given in Table 4., below.

Among the three substrates, $\mathrm{Si}_{3} \mathrm{~N}_{4}$ coated substrate exhibited the lowest error, ranging between -3 to $7 \%$, compared to that of $\mathrm{SiO}_{2}$ and c-Si ones. This result favors the use of $\mathrm{Si}_{3} \mathrm{~N}_{4}$ coated substrate for drieddroplet analysis over the other two substrate types. The precision is the agreement among individual analysis results of multiple measurements and usually expressed in terms of relative standard deviation of the measurements. It is the measure of reproducibility or repeatability of the analytical procedure under the same operating conditions. Precision values listed in Table 4 . were calculated from the relative standard deviation of five replicate measurements and, in general, ranges between minimum $6 \%$ and maximum $29 \%$. Among the three substrates, there is not much of a difference in terms of precision values for all the 


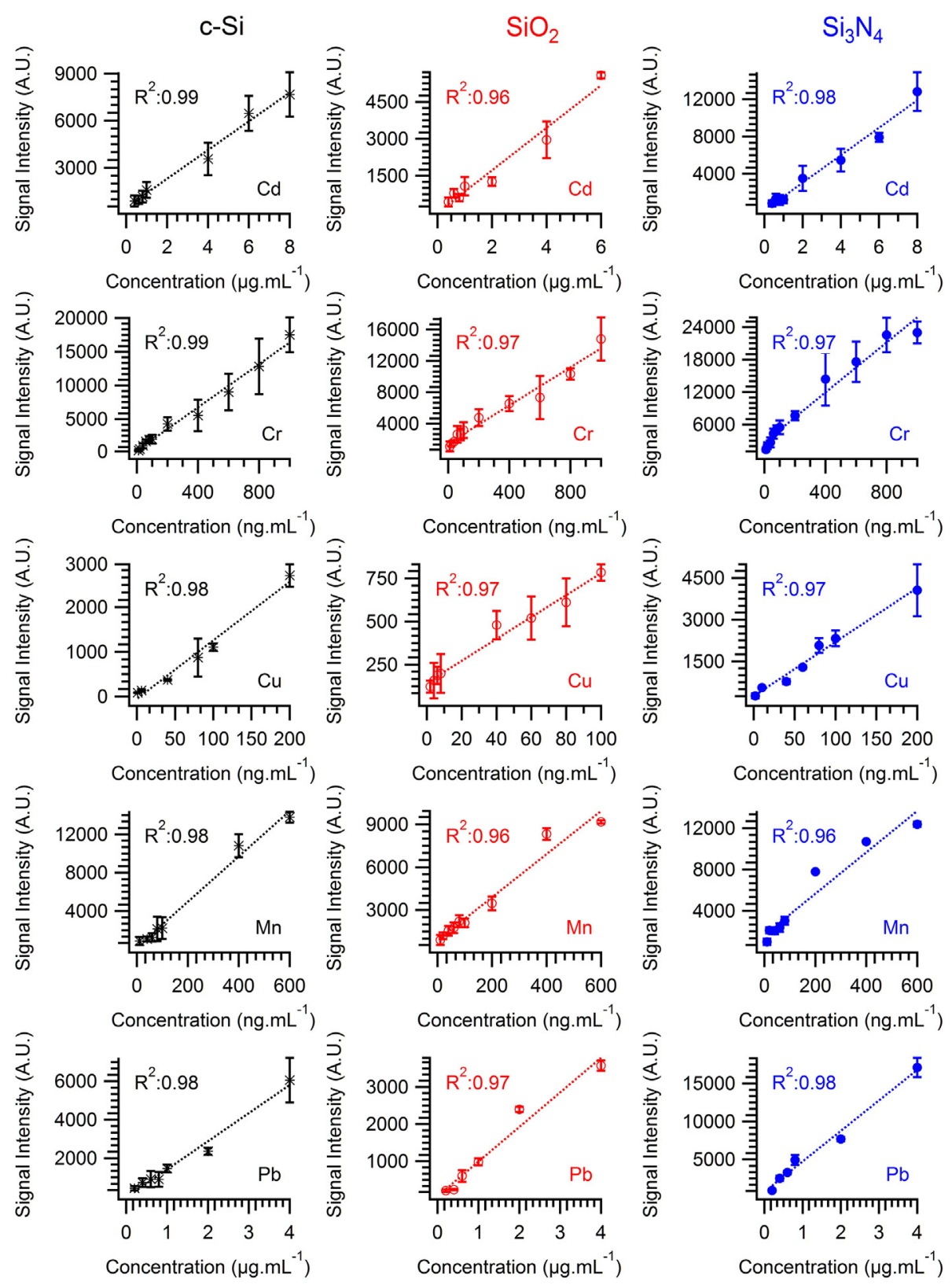

Fig. 7. Calibration graphs of each element with different substrates under optimum experimental conditions.

Table 3

Absolute and concentration based LOD values calculated from the calibration graphs of each elements.

\begin{tabular}{llllll}
\hline \multirow{2}{*}{ Elements } & $\mathrm{LOD}^{*}$ & \multicolumn{4}{l}{$\mathrm{LOD}^{* *}\left(\mathrm{ng} \mathrm{mL}^{-1}=\mathrm{ppb}\right)$} \\
\cline { 2 - 6 } & (pg) & $\mathrm{c}-\mathrm{Si}$ & $\mathrm{SiO}_{2}$ & $\mathrm{Si}_{3} \mathrm{~N}_{4}$ & Literature[cc] \\
\hline $\mathrm{Cd}(\mathrm{I}) 508.58 \mathrm{~nm}$ & 62 & 201 & 151 & 124 & $184[25], 420[18]$ \\
$\mathrm{Cr}(\mathrm{I}) 360.53 \mathrm{~nm}$ & 1.5 & 4 & 4 & 3 & $19[25], 25[18]$ \\
$\mathrm{Cu}(\mathrm{I}) 324.7 \mathrm{~nm}$ & 0.5 & 5 & 4 & 1 & $250[18]$ \\
$\mathrm{Mn}(\mathrm{I}) 403.08 \mathrm{~nm}$ & 2 & 18 & 7 & 4 & $6 \mu \mathrm{g}^{-1}[17]$ \\
$\mathrm{Pb}(\mathrm{I}) 405.78 \mathrm{~nm}$ & 11 & 80 & 37 & 22 & $118[18]$ \\
\hline
\end{tabular}

* Values are for Si3N4 substrate.

** $\mathrm{LOD}=3_{*} \mathrm{ST} . \mathrm{DEV} \mathrm{BG}_{(\mathrm{BG})} / \mathrm{SLOPE}$ of the calibration curve. elements studied.

\section{Conclusions}

In a search for finding a universal substrate for dried-droplet analysis of aqueous metal solutions by LIBS, three non-metallic substrates: bare silicon wafer (c-Si), $\mathrm{SiO}_{2}$ coated silicon wafer and $\mathrm{Si}_{3} \mathrm{~N}_{4}$ coated silicon wafer, were systematically investigated for their response to $\mathrm{Cd}$, $\mathrm{Cr}, \mathrm{Cu}, \mathrm{Mn}$, and $\mathrm{Pb}$ elements. For that purpose, aqueous droplets of $500 \mathrm{~nL}$ analyte solutions were placed on silicon wafer based substrates, dried at room temperature and were subjected to energetic laser pulses for plasma formation. It has been observed that, $\mathrm{Si}_{3} \mathrm{~N}_{4}$ coated substrate exhibits the highest sensitivity for the most prominent emission lines of the analyte elements studied, compared to the ones obtained with $\mathrm{SiO}_{2}$ coated and c-Si substrates. The enhanced sensitivity observed on $\mathrm{Si}_{3} \mathrm{~N}_{4}$ coated surface may be associated with the heat created by the strong absorption of intense laser radiation that may cause rapid heating of the dielectric surface. This may results in phase transition from solid to 
Table 4

Performance characteristics of the three silicon wafer based substrates in terms of accuracy and precision.

\begin{tabular}{|c|c|c|c|c|c|c|c|c|c|c|}
\hline & \multirow[t]{2}{*}{ Certified value (ng.mL ${ }^{-1}$ ) } & \multicolumn{3}{|c|}{ Determined value (ng.mL ${ }^{-1}$ ) } & \multicolumn{3}{|c|}{ Error (\%) } & \multicolumn{3}{|c|}{ Precision (\% RSD) } \\
\hline & & $\mathrm{c}-\mathrm{Si}$ & $\mathrm{SiO}_{2}$ & $\mathrm{Si}_{3} \mathrm{~N}_{4}$ & $\mathrm{c}-\mathrm{Si}$ & $\mathrm{SiO}_{2}$ & $\mathrm{Si}_{3} \mathrm{~N}_{4}$ & $\mathrm{c}-\mathrm{Si}$ & $\mathrm{SiO}_{2}$ & $\mathrm{Si}_{3} \mathrm{~N}_{4}$ \\
\hline $\mathrm{Cu}^{*}$ & $20.0 \pm 0.2$ & 37 & 21 & 20 & +87 & +4 & -0.5 & 21 & 17 & 19 \\
\hline $\mathrm{Mn}^{*}$ & $40.0 \pm 0.4$ & 62 & 46 & 43 & +56 & +16 & +7 & 12 & 12 & 12 \\
\hline $\mathrm{Pb}^{* * *}$ & 500 & 456 & 586 & 537 & -9 & +17 & +7 & 17 & 19 & 14 \\
\hline $\mathrm{Cd}$ & 500 & 433 & 378 & 487 & -13 & -24 & -3 & 24 & 29 & 23 \\
\hline $\mathrm{Cr}^{*}$ & $20.0 \pm 0.2$ & 95 & 18 & 20 & +373 & -10 & -0.5 & 23 & 23 & 6 \\
\hline
\end{tabular}

* CRM-TMDW-A reference sample. Used without dilution.

** ICP-MES reference sample. Dilution factor: 50 .

vapor without melting and help for readily transfer of the analyte for more efficient vaporization, atomization and excitation. It is also believed that, during this phase transition, gaseous nitrogen produced from the decomposition of $\mathrm{Si}_{3} \mathrm{~N}_{4}$ substrate provides an inert atmosphere which may facilitate the signal enhancement of the analyte atoms in laser induced plasma. Picogram amounts of absolute detection limits: $0.5 \mathrm{pg} \mathrm{Cu}, 1.5 \mathrm{pg} \mathrm{Cr}, 2 \mathrm{pg} \mathrm{Mn,} 11 \mathrm{pg} \mathrm{Pb}$ and $62 \mathrm{pg} \mathrm{Cd}$, on $\mathrm{Si}_{3} \mathrm{~N}_{4}$ coated substrates were achieved. Results demonstrate the analytical capability of the silicon wafer based substrates; especially $\mathrm{Si}_{3} \mathrm{~N}_{4}$ coated one, as a potential target material for dried-droplet analysis by LIBS technique. With the expense of time, technique can be improved more by applying sequential loading and drying strategy for quantification of solutions with sub-ppb concentrations.

\section{Acknowledgements}

Authors acknowledge TUBITAK for financial support through research grants 105T134, $108 \mathrm{~T} 376$ and 109T327 and IYTE-MAM staff for AFM analyses.

\section{References}

[1] L.J. Radziemski, D.A. Cremers, Laser Induced Plasmas and Applications, Marcel Dekker, New York, 1989.

[2] A.W. Miziolek, V. Palleschi, I. Schechter (Eds.), Laser-Induced Breakdown Spectroscopy: Fundamentals and Applications, Cambridge University Press, 2006.

[3] J.O. Cáceres, J.T. López, H.H. Telle, A.G. Ureña, Quantitative analysis of trace metal ions in ice using laser-induced breakdown spectroscopy, Spectrochim. Acta B 56 (6) (2001) 831-834.

[4] D. Alamelu, A. Sarkar, S. Aggarwal, Laser-induced breakdown spectroscopy for simultaneous determination of Sm, Eu and Gd in aqueous solution, Talanta 77 (2008) $256-261$.

[5] Y. Lee, S.W. Oh, S.H. Han, Laser-induced breakdown spectroscopy (LIBS) of heavy metal ions at the sub-parts per million level in water, Appl. Spectrosc. 66 (12) (2012) 1385-1396.

[6] A. Sarkar, S.K. Aggarwal, K. Sasibhusan, D. Alamelu, Determination of sub-ppm levels of boron in ground water samples by laser induced breakdown spectroscopy, Microchim. Acta 168 (1-2) (2010) 65-69.

[7] Z. Chen, H. Li, M. Liu, R. Li, Fast and sensitive trace metal analysis in aqueous solutions by laser-induced breakdown spectroscopy using wood slice substrates, Spectrochim. Acta B 63 (2008) 64-68.

[8] D.D. Pace, C. D'Angelo, D. Bertuccelli, G. Bertuccelli, Highly concentrated, ringshaped phase conversion laser-induced breakdown spectroscopy technology for liquid sample analysis, Spectrochim. Acta B 61 (8) (2006) 929-933.

[9] N.E. Schmidt, S.R. Goode, Analysis of aqueous solutions by laser-induced breakdown spectroscopy of ion exchange membranes, Appl. Spectrosc. 56 (2002) 370-374.

[10] S.H. Nam, S.W. Kwon, Y. Lee, Feasibility of separation and quantification of inorganic arsenic species using ion-exchange membranes and laser-induced breakdown spectroscopy, Anal. Lett. 51 (17) (2018) 2833-2846.

[11] K.M. Santos, J. Cortez, I.M. Raimundo, C. Pasquini, E.S.B. Morte, M.G.A. Korn, An assessment of the applicability of the use of a plasticized PVC membrane containing pyrochatecol violet complexing reagent for the determination of $\mathrm{Cu}^{2+}$ ions in aqueous solutions by LIBS, Microchem. J. 110 (2013) 435-438.

[12] Q. Lin, F. Bian, Z. Wei, S. Wang, Y. Duan, A hydrogel-based solidification method for the direct analysis of liquid samples by laser-induced breakdown spectroscopy, J. Anal. At. Spectrom. 32 (2017) 1412-1419.
[13] O. Lin, X. Han, J. Wang, Z. Wei, K. Liu, Y. Duan, Ultra-trace metallic element detection in liquid samples using laser induced breakdown spectroscopy based on matrix conversion and crosslinked PVA polymer membrane, J. Anal. At. Spectrom. 31 (2016) 1622.

[14] Z. Chen, H. Li, F. Zhao, R. Li, Ultra-sensitive trace metal analysis of water by laserinduced breakdown spectroscopy after electrical-deposition of the analytes on an aluminium surface, J. Anal. At. Spectrom. 23 (2008) 871-875.

[15] T. Jiang, Z. Guo, M. Ma, L. Fang, M. Yang, S. Li, J. Liu, N. Zhao, X. Huang, W. Liu, Electrochemical laser induced breakdown spectroscopy for enhanced detection of Cd(II) without interference in rice on layer-by-layer assembly of graphene oxides, Electrochim. Acta 216 (2016) 188-195.

[16] I. Gaubeur, M.A. Aguirre, N. Kovachev, M. Hidalgo, A. Canals, Speciation of chromium by dispersive liquid-liquid microextraction followed by laser-induced breakdown spectrometry detection (DLLME-LIBS), J. Anal. At. Spectrom. 30 (2015) 2541-2547.

[17] M. Aguirre, S. Legnaioli, F. Almod'ovar, M. Hidalgo, V. Palleschi, A. Canals, Elemental analysis by surface-enhanced Laser-Induced Breakdown Spectroscopy combined with liquid-liquid microextraction, Spectrochim. Acta B 79 (2013) 88-93.

[18] X.Y. Yang, Z.Q. Hao, C.M. Li, J.M. Li, R.X. Yi, M. Shen, K.H. Li, L.B. Guo, X.Y. Li, Y.F. Lu, X.Y. Zeng, Sensitive determinations of $\mathrm{Cu}, \mathrm{Pb}, \mathrm{Cd}$, and $\mathrm{Cr}$ elements in aqueous solutions using chemical replacement combined with surface-enhanced laser-induced breakdown spectroscopy, Opt. Express 24 (12) (2017) 13410-13417.

[19] R. Papai, R.H. Sato, L.C. Nunes, F.J. Krug, I. Gaubeur, Melted paraffin wax as an innovative liquid and Solid extractant for elemental analysis by laser-induced breakdown spectroscopy, Anal. Chem. 89 (2017) 2807-2815.

[20] M. Dell'Aglio, R. Alrifai, A.D. Giacomo, Nanoparticle enhanced laser induced breakdown spectroscopy (NELIBS), a first review, Spectrochim. Acta B 148 (2018) 105-112.

[21] N. Aras, S. Yalcin, Development and validation of a laser-induced breakdown spectroscopic method for ultra-trace determination of $\mathrm{Cu}, \mathrm{Mn}, \mathrm{Cd}$ and $\mathrm{Pb}$ metals in aqueous droplets after drying, Talanta 149 (2016) 53-61.

[22] L. Zheng, S. Niu, A.Q. Khan, S. Yuan, J. Yu, H. Zeng, Comparative study of the matrix effect in $\mathrm{Cl}$ analysis with laser-induced breakdown spectroscopy in a pellet or in a dried solution layer on a metallic target, Spectrochim. Acta B 118 (2016) $66-71$.

[23] X. Yang, Z. Hao, R. Yi, J. Li, H. Yu, L. Guo, X. Li, X. Zeng, Y. Lu, Simultaneous determination of $\mathrm{La}, \mathrm{Ce}, \mathrm{Pr}$, and Nd elements in aqueous solution using surfaceenhanced laser-induced breakdown spectroscopy, Talanta 163 (2017) 127-131.

[24] D. Bae, S.-H. Nam, S.-H. Han, J. Yoo, Y. Lee, Spreading a water droplet on the laserpatterned silicon wafer substrate for surface-enhanced laser-induced breakdown spectroscopy, Spectrochim. Acta B 113 (2015) 70-78.

[25] S. Niu, L. Zheng, A.Q. Khan, G. Feng, H. Zeng, Laser-induced breakdown spectroscopic detection of trace level heavy metal in solutions on a laser-pretreated metallic target, Talanta 179 (2018) 312-317.

[26] E.J. Hierra, J.A. Salazar (Ed.), Silicon Nitride: Synthesis, Properties and Applications, Nova Science Publishers Incorporated, 2012.

[27] A.E. Kaloyeros, F.A. Jove, J. Goff, B. Arkles, ECS J. Solid State Sci. Technol. 6 (10) (2017) 691-714.

[28] S. Zhu, G.Q. Lo, D.L. Kwong, Silicon nitride based plasmonic components for CMOS back-end-of-line integration, Opt. Express 21 (20) (2013) 23376-23390.

[29] P.A. Atanasov, E.D. Eugenieva, N.N. Nedialkov, Ablation of ceramics with ultraviolet, visible and infrared nanosecond laser pulses, J. Appl. Phys. 89 (2001) 2013-2016.

[30] N.G. Semaltianos, Nanoparticles by Laser Ablation, Crit. Rev. Solid State Mater. Sci. 35 (2) (2010) 105-124.

[31] E.A. Ryklis, A.S. Bolgar, V.V. Fesenko, Evaporation and thermodynamic properties of silicon nitride, Powder Metall. Met. Ceram. 8 (1) (1969) 73-76.

[32] D.R. Lide, CRC Handbook of Chemistry and Physics, 82nd edn., CRC, Boca Raton, 2001.

[33] A.P.M. Michel, Review: applications of single-shot laser-induced breakdown spectroscopy, Spectrochim. Acta B 65 (3) (2010) 185-191. 